\title{
CORPO, INTELIGENCIA E AS TRANSFORMAÇÕES NO MUNDO DO TRABALHO: REFLEXÕES A PARTIR DA MEDIAÇÃO DOS SABERES TÁCITOS*
}

\author{
Carlos Herold Junior ${ }^{* *}$
}

\begin{abstract}
RESUMO: O objetivo do estudo é investigar a presença do corpo nos processos produtivos mediados pela microeletrônica. Para isso, dividimos o texto em três momentos: no primeiro, estudamos como a relação entre corpo e trabalho é analisada pela área de Trabalho e Educação; no segundo, focalizamos autores que sublinham a presença do corpo no trabalho mediado pela microeletrônica, vendo essa presença por meio dos saberes tácitos demandados pelas rotinas de trabalho; no terceiro, evidenciamos alguns limites desses estudos. Como conclusão, podemos notar que, mesmo com o fato de os estudos sobre os saberes tácitos terem lançado bases para outro entendimento sobre a corporeidade no trabalho, não devemos tomar essas análises como fundamento para se acreditar no surgimento de uma forma de trabalho mais humana e que negue a divisão entre trabalho manual e intelectual. A luta pela afirmação ou a superação dessa dicotomia se dá histórica e politicamente, não sendo apenas um problema filosófico, científico ou organizacional.
\end{abstract}

Palavras-chave: Corpo. Trabalho. Trabalho e educação. Saberes tácitos.

BODY, INTELLIGENCE AND TRANSFORMATIONS IN THE WORLD OF LABOR: THOUGHTS BASED ON TACIT KNOWLEDGE MEDIATION

ABSTRACT: This paper analyzes the role of the body in the productive processes mediated by micro-electronics. Divided in three parts, it first shows how the body-labor relation is analyzed in the

\footnotetext{
* A pesquisa que eu origem a este artigo contou com o apoio do CNPq.

** Doutor em Educação e professor do Departamento de Pedagogia da Universidade Estadual do Centro-Oeste (UnICENTRO, PR).E-mail: carlosherold@bol.com.br
} 
fields of labor and education, then focuses on authors who emphasize the presence of the body in the labor mediated by micro-electronics, who see this presence in the tacit knowledge required by work routines, to finally evidence some limits of these studies. It draws the conclusion that, although the studies on tacit knowledge have created bases to understand corporeality at work differently, such analyses should not be used as a justification to believe that labor organization is nowadays more human and that the division between manual and intellectual labor is outdated. The struggle to affirm or overcome this dichotomy occurs both historically and politically and it should not be regarded only as a philosophic, scientific or organizational issue.

Key words: Body. Labor. Labor and education. Tacit knowledge.

\section{Considerações iniciais}

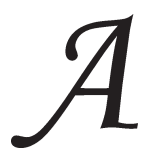

o analisarmos os processos de crise do capitalismo a partir da década de 1970, verificamos que os estudiosos da relação entre trabalho e educação se esforçam para pontuar de forma crítica o que se configura como mudança e o que deve ser assumido como permanência no que tange aos processos exploratórios do capital. Para colaborar com essas reflexóes, este estudo tem como intenção pôr em evidência um assunto discutido secundariamente por esses analistas: pretendemos evidenciar a necessidade de se discutir a questão da corporeidade nos processos de trabalho, tendo em vista a incorporação da tecnologia microeletrônica na produção.

Justificamos essa intenção pelo fato de a discussão da corporeidade do trabalhador ter sido posta de lado, sobretudo a partir da década de 1970, quando a propagação ideológica a respeito da "sociedade do conhecimento" ganhou terreno. Procuraremos mostrar que, justamente por conta das mudanças ocorridas na produção capitalista nesse contexto, é que essa discussão deve ser colocada, necessitando ser tematizada pelos estudiosos do trabalho, da educação e de suas relações.

Precisamos ter claro que a discussão sobre o corpo, seu cuidado, seu tratamento e sua educação, hoje, é alvo de uma grande quantidade de estudos e preocupações. O corpo é discutido nos meios de comunicação, nas conversas informais; pensa-se publicamente sobre a corporeidade, depositando nela o alvo de uma inquietação que pretende 
remediar um "esquecimento" e, com isso, construir uma vida com mais prazer e significado. ${ }^{1} \mathrm{Ou}$ seja, encontramos muitos pesquisadores, professores e interessados em geral em discutir a corporeidade, de um lado, e em discutir o mundo do trabalho, de outro. Porém, há uma sensível escassez de reflexões que se debrucem sobre a corporeidade e suas relações com esse mundo, principalmente à luz das transformações do processo do trabalho a partir da década de 1970.

Tendo como objetivo analisar a presença do corpo nos processos produtivos mediados pela microeletrônica, dividimos o estudo em três momentos: no primeiro, focalizaremos como as análises que estudam as transformaçōes no mundo do trabalho e seus impactos na educação demandam uma análise da corporeidade do trabalhador; na segunda parte, investigaremos como a questão da corporeidade vem sendo discutida tendo como suporte o debate relativo aos saberes tácitos dos trabalhadores que se ocupam de rotinas de trabalho mediadas pela tecnologia microeletrônica. $N a$ terceira, levantaremos alguns apontamentos críticos contra essas análises, sem perder de vista a relativa importância que elas possuem para a questão do corpo no trabalho.

\section{Corpo e trabalho nos estudos na área de Trabalho e Educação}

Discutir a corporeidade nas correntes transformações no mundo do trabalho é um ponto presente de forma não sistematizada em alguns estudos na área de Trabalho e Educação. Verificamos a presença latente da temática, principalmente quando é apresentado o relacionamento entre as categorias trabalho manual e trabalho intelectual. Em muitas análises preocupadas com a relação entre trabalho e educação, notamos um importante espaço para a discussão da corporeidade, principalmente nas que se ocupam das particularidades da reestruturação produtiva na demanda de novas exigências ao trabalhador, discutidas pela adjetivação do trabalho ou como manual ou como intelectual.

Ao observarem a atividade, ou a tarefa sendo executada, os analistas concluem que há predomínio ou de habilidades cognitivas (como é o caso nas reestruturações produtivas sob a égide da flexibilidade) ou de habilidades musculares e manipulativas. ${ }^{2}$ No trabalho de Ana Maria Resende Pinto (1991), verificamos esse fato quando ela afirma que “(..) a desqualificação do trabalho, em sua dimensão sensorial, pressupóe o 
Corpo, inteligência e as transformações no mundo do trabalho...

seu enriquecimento em outra dimensão: a cognitiva e intelectual, além da multiabilitação, o que não significa, necessariamente, maior controle sobre o seu processo de trabalho" (Pinto, 1991, p. 3). Para a autora, à medida que a produção incorpora o uso das máquinas microeletrônicas, a destreza manual passa a ser suplantada por uma relação mais intelectualizada com os equipamentos de trabalho. Antes de tudo, a matemática, a capacidade de abstrair e prever situações são as habilidades que passariam a ser requeridas.

Para essa autora, a dicotomia entre o trabalho intelectual e o trabatho manual aparece como uma balizadora importante na definição das novas formas de exploração do trabalho pelo capital. Além disso, a flutuação da atividade manual à intelectual estaria condicionada ao uso de um novo tipo de maquinário.

No interior de seus dados, entretanto, encontram-se passagens evidenciando que a referida dicotomia começa a ser rediscutida, no sentido de se verificar sua capacidade de apreender totalmente a complexidade ensejada com as mudanças no mundo do trabalho. Em uma das empresas pesquisadas, Ana Maria Resende Pinto (1991), ao dialogar com um dos responsáveis pelo processo de "cultura de qualidade", verifica que uma das questões enfatizadas é a preocupação de "sensibilizar o trabalhador para o seu corpo, a qualidade para consigo próprio (higiene, limpeza, estética e prazer)" (Pinto, 1991, p. 202).

Outro ponto levantado pela autora é a necessidade do envolvimento do trabalhador nas novas formas de trabalho. $\mathrm{O}$ fato de os equipamentos serem caros e sensíveis, raciocina a autora, demanda um comprometimento operário com o processo, o que vem se tornando mais necessário com "a transposição do trabalho 'manual' para intelectual (...)" (Pinto, 1991, p. 3). Além desse fato, observamos que essa transposição reduz o esforço físico necessário para a execução do trabalho, deixando a atividade laboral esvaziada de manifestações sensoriais e concretas (Pinto, 1991, p. 213).

Apontando possibilidades para uma discussão do corpo no trabalho, encontramos os trabalhos de Bianchetti (2001) e Kuenzer (2002a, 2002b). Bianchetti (2001) defende que até o termo "força de trabalho" começa a se chocar com as alterações do mundo do trabalho em consequência da perda de centralidade da atividade manual (p. 53). Com isso, a forma como o operário passa a ser concebido se transformaria 
consideravelmente. Kuenzer (2002a) também aborda esse assunto quando discorre sobre as alteraçôes na categoria competência sob a égide das readequações oriundas dos questionamentos levantados contra o taylorismo/fordismo. Para a autora, "força física" e "conhecimento" são conceitos que expressam duas concepçôes e procedimentos diferenciados, levados a cabo pelo "novo" mundo do trabalho. Entretanto, a preocupação em estudar o papel dos saberes tácitos, assumida pela autora, descortina uma possibilidade para a área de Trabalho e Educação contemplar as inquietações sobre a corporeidade, intencionalmente.

Desse modo, esses autores evidenciam uma determinada concepção sobre a corporeidade no mundo do trabalho, porém ainda não discutida e/ou sistematizada. As análises referidas evidenciam que há questôes a avançar no interior de suas reflexões, as quais, ao tematizarem outros objetos, discutem e afirmam um determinado entendimento sobre o corpo no trabalho. Torna-se necessário, então, pensar essa necessidade a partir das próprias possibilidades encetadas pelas pesquisas da área, no intuito de poder colaborar com a intenção primeira desses estudos, que é entender a mediação da educação no interior das transformações que ocorrem no mundo do trabalho.

Corpo, inteligência e trabalho: a mediação do saber tácito

$\mathrm{Na}$ área de Trabalho e Educação, vimos que, com o desenrolar das transformações produtivas, há a tendência de se polarizar corporeidade e inteligência. Essa tendência se soma a um debate mais amplo que ocorre paralelamente ao fato de se ambicionar a reprodução técnica dos processos intelectuais humanos. Com a progressão do desenvolvimento da automatização microeletrônica, bem como com o incremento da pesquisa e do interesse em torno da ambição de criar uma inteligência artificial, o debate sobre essa possibilidade se acirrou e os contendores puseram-se a defender seus pontos de vista de forma aguerrida. ${ }^{3}$ Dois dos analistas, que mais importância têm pelo fato de criticarem as pretensões das ciências cognitivas e da engenharia computacional em recriarem a inteligência humana em meios artificiais, ${ }^{4}$ são os irmãos Dreyfus e Dreyfus ${ }^{5}$ (1986). Em Mind over machine, eles se esforçam por demonstrar que, apesar do grande desenvolvimento das ciências mencionadas, o computador nunca poderá substituir com sucesso a cognição e o savoir-faire humanos. 
Ao analisarem a forma como Taylor lidou com a questão da inteligência na sua detalhada busca para racionalizar a produção, Dreyfus e Dreyfus (1986) afirmam que houve uma redução das particularidades e complexidades que os seres humanos apresentam ao julgarem e ao inferirem (p. 63).

É o mesmo caminho seguido por Collins (1992). O autor entende que saber e pensamento só são concebíveis socialmente. Entretanto, Collins (1992) faz questão de diferenciar a sua posição em relação à inteligência artificial e aos pontos levantados por Dreyfus e Dreyfus (1986). Ele explica o limite das máquinas não pelo fato de haver um nível além do qual as máquinas não consigam pensar. Ou seja, o autor não acredita que haja faculdades humanas informalizáveis, o que haveria é a necessidade de conceber o saber como social, como embasado nas relaçôes sociais, o que exclui, "automaticamente", a possibilidade de uma máquina pensar como um ser humano.

A idéia de Collins (1992) é que o homem, em alguns momentos, para a resolução dos problemas de sua existência cotidiana, age "mecanicamente". E é somente nesses atos que a máquina pode "copiar" o homem. Clot (1998) também enfatiza que a formalização das açôes não deve ser vista somente pelo lado negativo. Clot (1998) observa o lado liberador dos processos de formalização ao facilitarem ou proporcionarem novas aquisições. Assim, ele também sustenta que os desenvolvimentos das tecnologias informáticas, longe de serem exteriores, estão intimamente conjugados com a atividade cognitiva humana, justamente ao modificarem as condições nas quais e com as quais os homens produzem e se colocam tarefas com novos objetivos.

Tendo isso por base, Collins (1992) define formalização como um processo de simplificação que em nada significa uma ação mental superior. Para o autor é o contrário que é correto, afinal a formalização é um processo de "sacrifice d'une partie du potenciel human individuel" (1992, p. 74).

Um reflexo dessas ideias que defendem as especificidades humanas insuperáveis pela máquina é o surgimento desse mesmo debate sobre os processos produtivos. Um dos méritos dos estudos de Wood (1987) é a tentativa de incorporar esse debate e as mudanças pelas quais passava o capitalismo nas décadas de 70 e 80 . Como resultado, as análises dos processos de trabalho e da sociologia do trabalho começaram a 
rever alguns de seus preceitos para oferecerem esquemas explicativos condizentes com a complexidade que a nova situação apresentaria.

No interior desse debate sobre o poder de formalização e controle da força de trabalho pela gerência, baseado no incremento tecnológico, é que surge a discussão sobre os saberes tácitos ${ }^{6}$ do trabalhador. A distância entre a criação tecnológica, o manuseio produtivo dessa tecnologia e os limites das tecnologias, sanados pelo trabalho humano, apresenta como preocupação a análise do que poderíamos chamar de parte "viva" ou "inultrapassavelmente humana" do trabalho.

\section{Trabalho e inteligência: a mediação da corporeidade}

Com a incorporação de tecnologias de controle numérico, o debate sobre os processos de qualificação e desqualificação dos operadores passou a contar com a discussão sobre o papel a ser desempenhado pelos conhecimentos tácitos ${ }^{7}$ nas novas rotinas de trabalho. Uma das causas dos debates é a necessidade desses conhecimentos por parte dos operários, mesmo em trabalhos que são tradicionalmente vistos como desprovidos de qualquer tipo de qualificação. Wood (1987) assume que é esse o ponto que chama a atenção de suas análises, afinal ele clama por uma nova forma de enxergar o trabalho, como atividade.

Para Nonaka e Takeuchi (1997), a questão fundamental para uma epistemologia que possibilite o processo de mobilização e criação de conhecimento no interior de uma organização é a distinção entre conhecimento tácito e explícito, e a transformação do conhecimento tácito em explícito. Para isso, colocam Nonaka e Takeuchi (1997), é necessário refutar a divisão cartesiana entre sujeito e objeto ou "romper as dicotomias tradicionais". Ou seja, trata-se de aproveitar, organizacionalmente, o conhecimento individual existente em cada trabalhador, para ampliar a rede de conhecimento organizacional.

Gorz (2003) também apresenta reflexões em defesa do valor do conhecimento tácito ou informalizável dos trabalhadores. $\mathrm{O}$ autor defende, como resultado, que, ao estudar o trabalho hoje, não há a mesma possibilidade do passado em se prescrever uma tarefa. O que é necessariamente prescrito nos novos processos é a subjetividade operária que deverá estar disponível no momento da resolução dos problemas, geralmente imprevistos. O que as empresas precisam lançar mão é do processo 
Corpo, inteligência e as transformações no mundo do trabalho...

cotidiano de produção de si do operário e empregá-lo nas rotinas produtivas.

O autor faz questão de destacar uma reflexão acerca da cognição que privilegie a corporeidade humana, indo ao encontro, portanto, das abordagens cognitivas ancoradas na corporeidade. Verifica, igualmente, que o saber a ser utilizado pelo operário é informalizável, tendo sido transmitido a ele e a ser transmitido para outros no processo social de produção de si, que pode ser entendido, porém não formalizado em razão do número incontável de idiossincrasias pelas quais o processo é composto.

Seguindo a pista de Gorz (2003), notamos que a própria história da industrialização e o desenvolvimento tecnológico se dão na tensão entre essas duas formas de saberes. Nessa tensão, o autor verifica que o conhecimento científico, sobretudo na fase industrial, colocava-se do lado do capital não somente como fonte de dominação do trabalho vivo, mas também por ser inseparável do capital fixo.

No interior desse processo, Böhle e Milkau (1998) procuram verificar de que forma a incorporação de novas tecnologias altera a experiência cotidiana dos trabalhadores. Para isso, os autores realizam um estudo de campo buscando comparar a "experiência sensível" dos trabalhadores em tecnologias mecânicas e em tecnologias microeletrônicas. A obra de Böhle e Milkau (1998) desenha-se tendo como base o reconhecimento de que a rotina do trabalho é composta por particularidades, detalhes e incidentes, e que o recorrente debate entre trabalho prescrito e trabalho real deve ser plenamente levado em conta.

Para começar a lidar com essa problemática, os autores defendem uma concepção de trabalho, de homem e inteligência que é mediada pela corporeidade: "Le travail est une activité qui, au sens ergonomique du terme, convoque le fonctionnement du corps tout entier dans l'exercise d'une intelligence qui se déploie pour faire face à ce qui n'est pas déjà donné par l'organisation (prescrite) du travail” (Böhle \& Milkau, 1998, p. 37). Ao analisar as práticas e as idéias de Taylor, Clot (1998) nota que a intenção de separar a mão e o cérebro é válida somente quando incorremos na limitação de entendermos a tarefa observável e a atividade "real". De fato, diz Clot, "la main n'est jamais seulement la main" (1998, p. 75).

Tendo em vista essa importância, Jones e Wood (1984) vão deter-se na análise dos conhecimentos tácitos como meios para se buscar 
a relativa autonomia operária que existe por trás dos automatismos, dos condicionamentos e das regras do trabalho prescrito. Para Jones e Wood (1984), esses conhecimentos devem ser estudados, pois são eles os pontos de luta entre capital e trabalho. Além disso, o que antes se acreditava totalmente formalizado na máquina e na gerência taylorista passa para uma nova forma de entendimento.

Ferreira (2002), ao analisar o trabalho de petroleiros, observa que os indicadores dos painéis de controle não são suficientes para dar conta do processo. $\mathrm{O}$ autor mostra que os ruídos, os cheiros, as posições das válvulas, enfim, uma gama imensa de "índices" não prescritos, são de grande utilidade. $\mathrm{O}$ que torna esse processo ainda mais complicado é o fato de ele ser contínuo, sendo necessário o revezamento de turnos, o que faz com que essa "captação" de índices seja modificada substancialmente.

Já Lima e Silva (2002a), tendo por objetivo analisar os processos de objetivação do saber prático em rotinas de trabalho mediadas pela microeletrônica, defendem que a tecnologia flexível coloca dificuldades qualitativamente diferentes em relação aos processos de objetivação do saber anteriormente empregados. Os autores verificam que em processos altamente guiados pela automatização, o papel dos operadores assume um caráter de vigilância e de retomada do processo em caso de instabilidade, o que faz com que algumas habilidades manuais e cognitivas sejam extremamente úteis. Além disso, assiste-se na atualidade a uma fluidificação dos processos produtivos em que antigos termos gerais, como "supervisão", "força", "movimento" etc., tornam-se limitados para definir se uma tarefa é automatizada ou humana, e mesmo a existência dessa última dicotomia acaba por ser inviabilizada. Isso não impede os autores de verificarem que algumas práticas permanecem e que seria possível falar em "taylorismo mental" como um conceito que possibilitasse entender a forma como velhas práticas penetram em realidades socialmente e tecnologicamente diferentes.

Lima e Silva (2002b) notam que a relação entre objetivação do saber prático e desqualificação não deve ser vista de forma automática. Afinal, além de não haver separação entre as formas práticas e teóricas/ formalizáveis do saber, os níveis superiores de conhecimento sempre se apoiam e requerem os níveis inferiores. Para os autores, as perdas de habilidades perceptivas, por exemplo, devem ser sempre postas no âmbito da coletividade, no qual essas habilidades são reconstituídas. Partindo de suas pesquisas de campo, os autores subsidiam o fato de operadores 
Corpo, inteligência e as transformações no mundo do trabalho...

buscarem indícios com operadores de outros setores para verificar se seus painéis de controle estão fidedignos.

\section{O conhecimento tácito nas novas tecnologias como evidência corporal da inteligência operária}

Rabinbach (1992), ao estudar o processo de formação das ciências do trabalho no final do século XIX e nas primeiras décadas do século $\mathrm{xx}$, observa que, nesse momento, a idéia de human motor associada ao corpo humano é a metáfora explicativa mais recorrente para se refletir sobre os limites e os potenciais do trabalho. Extremamente coadunado com os limites e desenvolvimentos da ciência naquele momento, o corpo humano, como fonte de energia e movimento, ocupava um lugar central nas reflexões.

Entretanto, com as transformações em curso e, tendo por base as manifestações teóricas vistas na área de Trabalho e Educação, o corpo-energia cedeu espaço ao corpo-informação, oscilando a relevância das reflexôes sobre o corpo para as feitas sobre a inteligência: processar informação passou a ser a valência preponderante em relação à produção de energia.

Como reação a essa corrente e, no nosso entender, limitada forma de encarar as transformaçôes no mundo do trabalho, há especialistas que, acreditamos, devem ser acompanhados pela área de Trabalho e Educação no aprofundamento de suas análises.

Dejours (1993) é um dos autores que defendem a necessidade de se buscar uma visão mais complexa sobre o trabalho, visto como atividade. Ele afirma que é necessário rever o posicionamento para o qual os trabalhadores se alinham "automaticamente" às normas e às prescriçôes advindas da estrutura econômica e social.

Tendo isso claro, Dejours (1993) busca entender as formas com as quais os operários lidam com as tarefas e as táticas de mobilização de seu conhecimento para fazer face tanto aos limites quanto aos prejuízos impostos pela gerência ao prescrever os procedimentos. Para isso ele vai buscar entender a inteligência operária focalizando o savoir-faire e/ou saberes tácitos.

A primeira observação feita pelo autor, depois de anunciar essa intenção, é: a principal característica da "(...) inteligência prática é, do ponto de vista psíquico, estar fundamentalmente enraizada no corpo" 
(idem, ibid., p. 285). Consequentemente, complementa o autor: "Este envolvimento do corpo na tarefa, assim como a primazia da percepção, coloca a inteligência prática, tanto em se desencadear quanto em sua intencionalidade, numa temporalidade atual que somente a fenomenologia permite captar e comentar" (p. 285-286).

Essa forma de afirmar o envolvimento corporal na inteligência, consequentemente, distingue-se do raciocínio lógico, sem podermos dizer que são inteligências que ocorrem em espaços e tempos diferentes. $^{8}$ Atribuindo um grande desempenho e importância a essa inteligência, o autor acrescenta que é necessário entender o "lugar que ocupa o corpo inteiro numa tarefa que se descreve erradamente como estritamente intelectual, e depois a preeminência temporal da prática sobre a consciência (...)" (p. 288). Isso não quer dizer, por sua vez, ausência de pensamento. $\mathrm{O}$ que vai diferir a inteligência prática do pensamento é o que Dejours (1993) denomina como a segunda característica da inteligência prática: a "(...) sua capacidade de auferir mais importância aos resultados da ação, do que ao caminho utilizado para atingir os objetivos" (p. 289).

Dejours (1993) não se esquece de mencionar que é a própria economia de esforço, entendido no sentido "energético", que constitui outra forma de solidariedade entre inteligência e corpo. Porém, entender essa relação somente por essa questão seria limitar o envolvimento corporal nas tarefas intelectuais no ambiente de trabalho. Ao citar a terceira característica da inteligência prática, Dejours (1993) afirma a ostensiva presença dessa inteligência e, como resultado, do corpo em todo o processo de trabalho (p. 289).

Depois dessa análise, Dejours (1993) nota que essa característica corporal da inteligência está presente até mesmo nas atividades teóricas. Não se pode conceber o saber prático como uma manifestação eminentemente corporal. O saber prático também é passível de ser encontrado e executado por pessoas encarregadas de raciocínios os mais abstratos.

Seguindo o mesmo caminho, Böhle e Milkau (1998) possuem como base conceitual o que eles chamam de atividade subjetivante, podendo ela ser entendida como o envolvimento individual total na realização das mais variadas tarefas e que está intimamente conectado com a construção de uma autoimagem perante o mundo. $\mathrm{O}$ que os autores defendem é que no interior dos processos produtivos, mesmo os mediados 
Corpo, inteligência e as transformações no mundo do trabalho...

pela tecnologia microeletrônica, essa atividade subjetivante está presente, sendo necessário investigar as formas com as quais essa atividade se apresenta.

Os autores assumem que a já percebida redução das exigências corporais nas rotinas de trabalho não é cuidadosamente analisada. No que diz respeito à percepção operária sobre a exigência física do trabalho, os autores mostram que, apesar de afirmarem a "suavização" das rotinas de trabalho nos ambientes micro-eletrônicos, isso não quer dizer que a diminuição da exigência muscular seja sempre bem-vinda de forma óbvia, na medida em que essa exigência é um dos constituintes para uma determinada identidade masculina ao trabalho. Além da questão de gênero, está a constatação de que é a atividade subjetivante que regula e que possibilita a execução de meios para controlar a antiga exigência física no trabalho ou vê-la de uma forma não-negativa (1998, p. 61). Mesmo nos novos processos, os depoimentos operários colhidos pelos pesquisadores alemães chamam atenção à exigência corporal, agora relacionada com a tensão ocasionada pela constante observação e vigilância, impactando olhos, pescoço, cabeça, coluna, o que, de acordo com os autores, é um primeiro sinal, o mais facilmente observável, de que a corporeidade é algo a ser considerado.

Para analisar essa presença da corporeidade no processo produtivo, é preciso, em primeiro lugar, assumir os sentidos e a percepção de forma diferente da qual são entendidos na atualidade. Os autores criticam a abordagem predominante, na qual os sentidos captariam fisicamente os dados do ambiente para serem processados mentalmente. ${ }^{9}$ Isso, entre outras coisas, acarreta o fato de que o savoir-faire é tido como um nível inferior em relação ao pensamento, pois somente possibilita a execução "mecânica" das tarefas prescritas. Para Böhle e Milkau (1998), mesmo as abordagens ecológicas ${ }^{10}$ caem nesse erro. Os autores buscam refutar qualquer tipo de relação hierárquica entre os aspectos práticos e teóricos, particulares e gerais.

Isso tem como consequência a certeza de que a percepção sensível é um processo muito mais complicado do que afirma a fórmula racionalista e/ou empirista. O processo de recepção e análise dos dados perceptivos é, sempre, subjetivo e dependente das particularidades contextuais. É por isso que a atividade subjetivante é entendida como algo que toma o indivíduo em sua globalidade e sua consideração no mundo do trabalho é plena em consequências para os trabalhadores. 
Böhle e Milkau (1998) constatam que o controle da atividade subjetivante tanto por parte do operário quanto por parte da gerência, é algo difícil. Soma-se a isso o fato de as tecnologias implicarem a mudança constante de seus métodos, acarretando um processo contínuo de envolvimento e adaptação das experiências adquiridas diante das novidades assumidas pela organização. Entretanto, eles defendem que para a execução do trabalho, mesmo com as máquinas de controle numérico, é necessária uma "certeza subjetiva", sem a qual o processo não funcionaria.

Zuboff (1988) também chama atenção para questões semelhantes ao analisar que com o processo de incorporação das novas tecnologias, transformações intensas nas rotinas do trabalho acontecem. Estas transformações são percebidas pelos operadores que ela estuda como uma flutuação ocasionada justamente nos limites entre os conhecimentos formalizados e tácitos, e que influencia diretamente a forma de aplicação e a utilidade do conhecimento acumulado pela experiência laboral e embasado no corpo. A autora, então, acredita que a discussão sobre as novas exigências do mundo do trabalho pode ser entendida na revisão da presença corporal do trabalho que, até então, é visto como fonte tanto de "esforço", quanto das "skills" ou habilidades.

A discussão de Zuboff (1988) relaciona a presença corporal com a questão do conhecimento tácito e não somente com a questão energética. Neste sentido, ela também expressa a aproximação da discussão do corpo com a inteligência, com o processamento de informação, típico das análises que começam a surgir nos anos de 1970, 1980 e 1990. A autora nota que, com as transformações que vêm ocorrendo, o envolvimento intelectual assume um caráter mais abstrato relacionado à manipulação mental de símbolos. Zuboff (1988) expressa a forma como o corpo passa a ser considerado: de forma diferente nos processos de trabalho, não significando que ele seja posto de lado, mas, sim, questionado.

Para a autora, a questão do corpo não deve ser vista como uma questão de mais ou menos força, resistência ou qualquer outra valência física associada ao buman motor (Rabinbach, 1992). O corpo, para Zuboff (1988), passa a ser valorizado em seu papel para a viabilização do conhecimento necessário para os processos produtivos. Mesmo afirmando que houve um aumento na importância dos saberes explícitos ou formais para a execução das tarefas, a autora diz que o papel dos saberes tácitos, apesar de diferente, ainda é sentido, sobretudo, quando a questão 
Corpo, inteligência e as transformações no mundo do trabalho...

relacional e linguística é levada em conta para viabilizar a troca e a análise das informações sobre o processo produtivo. Consequentemente, longe de afirmar hipóteses para uma possível superação do corpo nos ambientes de trabalho, a autora defende: "the body's traditional role in the production process (as a source of effort and/or skill in the service of acting-on) is also transformed" (p. 393).

Com isso, podemos ver que a questão dos saberes tácitos, impulsionados pelas características da incorporação das novas tecnologias, coloca o corpo no centro de um dos grandes debates sobre o conhecimento no trabalho. Essa constatação é importante: ela nega toda uma tradição de análise do corpo no trabalho, que via o corpo como gasto de energia, e passa a vê-lo como processamento pessoal e circunstancial de informação, da mesma maneira que problematiza a ideia de que o trabalho dispensa o corpo pela recorrência aos processos de análise e tomada de decisão ante o que Zarifian (2001) chama de eventos.

Por fim, caminhando no mesmo sentido que o das análises apresentadas, mas avançando pela consideração de questóes históricas e políticas mais amplas, está a abordagem desenvolvida sobre o corpo no trabalho apresentada por Negri e Hardt (2000), em Império. Os autores elaboram uma abordagem do corpo no trabalho baseando-se no reconhecimento e na crítica dos operaístas italianos. Para Negri e Hardt (2000), a apropriação que é feita do conceito de general intellect por parte daqueles autores é ingênua pelo fato de se basear excessivamente em questões intelectuais, negligenciando as questões tocadas (e que são todas as questôes) pelo biopoder, tidas como "centrais". Após essas ponderações, os autores tiram conclusões que, por relacionarem-se diretamente à temática desta análise e suas consequências históricas e políticas, devem ser citadas:

Cerveaux et corps ont toujours besoin des autres pour produire de la valeur, mais ces "autres" dont ils besoin ne sont pas nécessairement fournis par le capital et par ses capacités d'orchestrer la production. De nos jours, la productivité, la richesse et la création de surplus sociaux prennent la forme d'interactivité coopératrice par l'intermédiaire de réseaux linguistiques, communicationnels et affectifs. Dans l'expression de sa propre énergie créatrice, le travail immatériel semble ainsi fournir le potentiel pour une sorte de communisme spontané et élémentaire. (Negri \& Hardt, 2000, p. 359; sem grifos no original) 
Essas ideias trazem a contribuição de responderem a uma nova necessidade colocada pelas transformações que ocorrem na sociedade, lançando as bases e aproveitando bases lançadas de uma representação de corpo diferente daquela que foi feita no capitalismo industrial, forjado no século XIX e permanente até a década de 50 do século xx. Negri e Hardt (2000), ao apropriarem-se dessa análise, apontam para conclusões que devem ser, por sua vez, alvos de investigação e crítica, justamente pelo fato de os autores basearem suas reflexões sobre uma concepção de trabalho limitada.

Críticas às análises da corporeidade no trabalho pela inteligência

Esse limite dá espaço para um posicionamento que vê no corpo uma essência inescapável do ser humano, ou no trabalho mediado pela microeletrônica uma humanização, uma recuperação da corporeidade humana, sugerindo, assim, que o mundo do trabalho e a questão do corpo no trabalho pudessem ser abordados diretamente, sem a consideração de numerosas variáveis intervenientes no processo.

Há de se ter claro que o potencial analítico desses estudos pode ser maximizado se eles se pautarem por uma consideração sobre o trabalho humano que o enxergue, ao mesmo tempo, em sua dimensão concreta e abstrata, tal qual definida por Marx (1994).

Para ilustrar essa possibilidade, Marx (1994), no capítulo XIV de $O$ capital, defende que a relação entre homem-natureza só se dá mediada pela sociedade, ao mesmo tempo em que a funda. Marx (1994) demonstra um entendimento de corpo no trabalho em que a atividade concreta de produção da existência, comum em todas as sociedades, só acontece com a concorrência social de todas as capacidades humanas. Neste sentido, Vasquez (1990), retomando esse encaminhamento, oferece uma importante consideração ao afirmar que: "O papel predominante dos meios de produção, acentuado por Marx, longe de eliminar a presença do homem concreto, como sujeito da produção, o revela inequivocamente" (p. 196).

Entretanto, essa "presença", sublinha Marx (1994), é socialmente mediada, tendo como resultado que, no caso do capitalismo: 
Para trabalhar produtivamente não é mais necessário executar uma tarefa de manipulação do objeto de trabalho; basta ser órgão do trabalhador coletivo, exercendo qualquer uma das suas funçōes fracionárias. A conceituação anterior de trabalho produtivo, derivada da natureza da produção material, continua válida para o trabalhador coletivo, considerado em conjunto. Mas não se aplica mais a cada um de seus membros, individualmente considerados. (Marx, 1994, p. 584)

Marx evidencia, assim, que a base do processo de produção social sempre é a relação entre o homem e a natureza (o que faz com que o trabalho das "mãos" e o trabalho do "pensamento" sejam dificilmente diferenciados), mesmo que essa relação esteja cada vez mais penetrada pela necessidade, no caso do capitalismo, da produção de mais-valia. Não é esse o parâmetro de análise seguido pelos pesquisadores que foram analisados neste estudo, quando eles concebem o corpo no trabalho. $\mathrm{O}$ apelo que fazem Negri e Hardt (2000) ao biopoder que alastra as determinações do capital para além do mundo do trabalho, chegando a toda a sociedade, redunda em uma crítica às "limitaçōes" da forma de entender o capitalismo desenvolvido por Marx baseado na teoria do valor-trabalho. O que Negri e Hardt (2000) defendem é a incomensurabilidade do trabalho, baseada na sua "imaterialidade".

Lessa (2005) critica veementemente a expressão "imaterial”, dada por Negri e Hardt (2000) à "nova configuração” do trabalho. Lessa (2005) observa que eles associam pensamento e análise com o termo "imaterial", implicando uma redução profunda das considerações sobre a "concreticidade" (no seu sentido social e não somente como embasada corporalmente) que a consciência possui, sobretudo quando o trabalho é levado em conta tanto como meio de relação entre homem e natureza quanto na sua forma especificamente capitalista.

Para Lessa (2005), a materialidade, a concreticidade dos processos produtivos, está, também, nas relações sociais que os homens estabelecem para a efetivação e satisfação das suas necessidades. A atividade, o observável, apesar de importante, não contém em si a totalidade, a concreticidade social que, para Lessa (2005), tem uma característica diferente da concretude natural. Como resultado:

(...) a imaterialidade que pretendem imputar ao trabalho contemporâneo é decorrência de uma concepção de materialidade que a identifica às formas naturais. Perdem, com isso, a possibilidade de reconhecerem as ideias (os complexos ideológicos) como forças materiais na determinação da 
história dos homens. Perdido o elo ontológico entre a natureza e o mundo dos homens, entre a materialidade natural e a materialidade social, não lhes resta alternativa ao economicismo senão o idealismo. (Lessa, 2005, p. 43-44)

Os mesmos limites podem ser notados nas análises de Gorz (2003). Para Prado (s.d.a), ele mistifica a questão do trabalho na atualidade quando analisa o capitalismo com o conceito de imaterial. Assumindo como pressuposto o fato de as transformaçôes darem ao trabalhador as condiçôes de ser sujeito na concreticidade do processo de trabalho, Prado (s.d.a) nota que o fato de isso não significar uma realidade para todo o modo de produção evidencia mais uma das contradições que constituem o capitalismo.

Essa condição de sujeito dada pelo desenvolvimento das forças produtivas capitalistas é a base, como vimos, para o estudo das questões relativas aos saberes tácitos, utilizados para a visualização do corpo no trabalho como base dos processos interpretativos e decisórios nas rotinas de trabalho mediadas pela microeletrônica. A importância dos $\mathrm{co}$ nhecimentos tácitos para a execução das tarefas não pode ser negada. É justamente neste aspecto incomensurável, informalizável, idiossincrático do trabalho que reside um dos pontos centrais para a dissipação de todo um conjunto de análises que, ao buscarem "valorizar" o trabalho vivo, afirmam a superação do entendimento do capitalismo baseado na lei do valor-trabalho, definida por Marx.

Para Prado (s.d.b) a questão da inteligência prática ou conhecimento científico deve ser, então, encarada no interior das relações sociais, pela mediação do relacionamento entre trabalho abstrato e concreto, no amplo processo de divisão social de trabalho, e não reduzida somente ao âmbito individual. Gorz (2003), ao defender o conhecimento científico formalizável nas máquinas, a inteligência operária individual e enraizada na corporeidade e na presença operária nas rotinas do trabalho concreto, desconsidera que essas capacidades humanas exercidas no trabalho só podem ser entendidas pelo imperativo da mensuração e da troca de mercadorias.

Prado (s.d.a) também reprova Gorz (2003) por ter identificado as potencialidades e as qualidades humanas como capital fixo. Isso é possível de ser visto no caráter fetichista da expressão "capital humano", que esconde o fato de o homem só aparecer como capital no processo de produção. Se homem e suas características são conteúdos do capital, não há 
como dizer que o capital é humano; não podendo daí Gorz (2003) concluir que o capital e o pleno desenvolvimento do indivíduo são coisas comparáveis, conclusão esta da qual Negri e Hardt (2000) também partilham. Sobre isso Lessa (2005) afirma que "Assim como o ser humano é muito mais que o trabalho abstrato do qual é portador, as relações sociais são muito mais que o processo de autovalorização do capital” (p. 60).

\section{Apontamentos finais}

Para explicar o funcionamento do modo de produção capitalista, Marx (1994) constantemente se refere ao valor-de-uso/valor-de-troca, trabalho concreto/trabalho abstrato, trabalho vivo/trabalho morto, capital constante/capital variável, definindo a produção capitalista como consumo do trabalho, como capital produzido pelo trabalho e o trabalho como passível de ser realizado no capitalismo somente quando dirigido para a produção de mais-valia. Processo esse que só tem sentido e só acontece socialmente.

Analisar a corporeidade no trabalho, como base de uma presença cognitiva para a resolução de problemas postos pelos artefatos tecnológicos no decorrer da produção, é uma expressão reduzida do amplo processo descrito por Marx (1994). O que queremos é entender as potencialidades humanas, criadas e limitadas historicamente na práxis produtiva, não como reduzidas ao homem indivíduo, nem ao homem como gênero, mas, sim, na totalidade das relações sociais estabelecidas no interior de um modo de produção. Negri e Hardt (2000), Gorz (2003), Zuboff (1988), Dejours (1993) e Böhle e Milkau (1998), ao enxergarem o processo de trabalho ou como atividade, como "concreto", ou como algo pulverizado, imaterial, perdem de vista a "objetividade" corporal, intelectual, emocional do homem, que é possível de ser captada na concretude das relaçôes sociais dos diferentes modos de produção que têm ou que tiveram lugar na história. É nessa concretude, e não somente no decorrer e na observação da execução de uma tarefa, que as dicotomias físico/intelectual, razão/emoção, ou a luta para superá-las valorizando uma em detrimento da outra, podem ser ultrapassadas.

$\mathrm{O}$ estudo possibilitou-nos entender por que os analistas que enfatizam a importância dos saberes tácitos assumem, como consequência do reconhecimento do corpo nos processos relativos à inteligência, 
posicionamentos criticáveis sobre a configuração do trabalho no capitalismo, tais como os que advogam o fim da divisão entre trabalho intelectual e manual, ou aqueles que afirmam que essa divisão nunca existira na história. Eles, ao partirem de uma concepção de objetividade limitada (para eles, nada mais concreto que o corpo), ao tentarem enxergar as potencialidades corporais na "concreticidade" dos processos produtivos (entendida na sua acepção limitada advinda do mundo natural, e não como o concreto proporcionado pela análise que objetive a apreensão da totalidade social), hesitam nos limites de suas próprias análises, defendendo ao mesmo tempo a "imaterialidade" do trabalho.

A integralidade humana é a produção social da existência (e é, também, seu produto) que se dá na história. Ela acontece imersa na luta, consciente ou não, pela transformação ou manutenção de determinadas relações sociais de produção. E é nessa luta que reside a possibilidade, também, de construção de uma compreensão que dê conta dessa integralidade e que fortaleça a construção de uma sociedade em que a práxis produtiva e o entendimento dessa práxis não apareçam como coisas diferentes. Para isso, mostramos que um passo importante é a consideração mais detida, por parte da área de Trabalho e Educação, sobre as questóes concernentes à corporeidade da classe-que-vive-do-trabalho.

\section{Recebido em outubro de 2008 e aprovado em dezembro de 2008.}

\section{Notas}

1. Ver Juvin (2005), bem como Le Breton (2003).

2. Mesmo sem ser da área de Trabalho e Educação, a obra de Marie (2004) expressa a maneira a mais vulgar como o senso comum pensa o trabalho humano, apoiado em conceitos frágeis, tais qual "sociedade do conhecimento".

3. Para uma idéia da forma acirrada que acontece o debate, ver Bolo (1996).

4. Explica Dosse (2003, p. 221): "O fracasso da inteligência artificial na composição de modelos de certas funções simples 'aumentou esse respeito pelos instrumentos do senso comum. Neste sentido, há uma reabilitação do senso comum”.

5. Sobre as reflexốes de Dreyfus, afirmam Yanarella e Reid (1996, p. 191): "Building on the vital contributions of Martin Heidegger, Maurice Merleau-Ponty, and Michael Polanyi and their interest in how human being use tools, Dreyfus has insisted on the role of the body in intelligent behavior, arguing that 'man's skillful bodily activity as he works to satisfy his needs generates the human world"”. 
Corpo, inteligência e as transformaçôes no mundo do trabalho...

6. Temos claro que a advertência feita por Dosse (2003, p. 221), sobre as consequências que essa valorização do tácito, do informalizável, do "saber-encarnado", “(...) coloca um problema de fundo às ciências humanas em geral, pois a reavaliação do senso comum pode chegar, em certos casos extremos, até a retomar pura e simplesmente os considerandos da psicologia popular".

7. Michel Polanyi (1974, p. 237) tem o crédito de ter se dedicado pioneiramente à "tacit dimension" da inteligência. Ele inicia sua obra Personal knowledge - towards a post-critical philosophy, publicada em 1958, dizendo: "Skilful knowing and doing is performed by a subordinating a set of particulars, as clues or tools, to the shaping of a skilful achievement, whether practical or theoretical" (p. vii). O autor prima pela necessidade de fundir o "conhecimento pessoal" com o "conhecimento objetivo". Para isso, entre outras coisas, ele critica a "Epistemologia Leninista-Marxista" (p. 237).

8. Sobre essa questão, Pezé (2002, p. 144-145), partindo também dos estudos de Dejours e apoiando-se na psicanálise, afirma: "La dimension corporelle de l'intelligence que nous mobilisons dans le travail est différente de l'activité logique. Évaluer la qualité d'un matériau du plat de la de main, identifier à l'oreille un moteur défaillant, visualiser, dès l'incision, la déchirure d'un tendon, 'sentir' l'angoisse du patient, sont autant de situations de travail mobilisant des données perceptives, mais aussi, derrière l'information sensitive présente, toute l'histoire de notre corps, personelle et professionnelle. Le pulsionnel du corps investit le réel du travail jusqu'au surgissement de la réponse inventive. Perception, interprétation, diagnostic, action engagent bien plus que notre intellect. Pour le colosse qui danse sur son échaufaudage comme pour le chirurgien peaufinant une suture, pour la cassière qui vous reconnaît et vous sourit, pour la psychanalyste qui interprète les corps, travailler implique sortir de la prescreption. (...) Travailler passe par l'énigme de la mobilisation du corps, creseut entre le pulsionnel, le physiologique et le symbolique".

9. Para uma análise antropológica dos sentidos humanos, ver Le Breton (2006).

10. Os autores citam as obras de Gibson $(1966,1986)$.

\section{Referências}

BIANCHETTI, L. Da chave de fenda ao laptop: tecnologia digital e novas qualificaçôes: desafios à educação. Petrópolis: Vozes; Florianópolis: UFSC, 2001.

BÖHLE, F.; MILKAU, B. De la manivelle à l'écran: l'évolution de l'expérience sensible des ouvriers lors des changements technologiques. Paris: Eyrolles, 1998.

BOLO, J. Philosophie contre intelligence artificielle. Paris: Lingua Franca, 1996. Disponível em: <http://jbolo.exergue.com/index.html>. Acesso em: 4 ago. 2006.

CLOT, Y. Le travail sans l'homme?: pour une psychologie des milieux de travail et de vie. Paris: La Découverte, 1998. 
COLLINS, H.M. Experts artificiels: machines intelligentes et savoir social. Paris: Seuil, 1992.

DEJOURS, C. Inteligência operária e organização do trabalho: a propósito do modelo japonês de produção. In: Hirata, H. (Org.). Sobre o "modelo" japonês: automatização, novas formas de organização e de relações de trabalho. São Paulo: EDUSP, 1993.

DOSSE, F. O império do sentido. Florianópolis: EDUSC, 2003.

DREYFUS, H.; DREYFUS, S. Mind over machine: the power of human intuition and expertise in the era of the computer. New York: The Free, 1986.

FERREIRA, L.L. O trabalho dos petroleiros. In: Duarte, F. (Org.). Ergonomia e projeto na indústria de processo contínuo. Rio de Janeiro: Lucena, 2002. p. 64-74.

GIBSON, J.J. The senses considered as perceptual systems. Boston: Houghton Mifflin, 1966.

GIBSON, J.J. Ecological approach to visual perception. Hillsdate: Lawrence Erlbaum, 1986.

GORZ, A. L'immatériel: connaissance, valeur et capital. Paris: Galilée, 2003.

JONES, B.; WOOD, S. Qualificaçôes tácitas, divisão do trabalho e novas tecnologias. (Tradução livre de Jacquelina Imbrizi). Sociologie du Travail, Paris, v. 26, n. 4, p. 84, 1984.

JUVIN, H. L'avènement du corps. Paris: Gallimard, 2005.

KUENZER, A.Z. Exclusão includente e inclusão excludente: a nova forma de dualidade estrutural que objetiva as novas relaçóes entre educação e trabalho. In: LOMBARDI, J.C.; SAVIANI, D.; SANFELICE, J.L. (Org.). Capitalismo, trabalho e educação. Campinas: Autores Associados; HISTEDBR, 2002a. p. 77-96.

KUENZER, A.Z. Conhecimento e competências no trabalho e na escola. Boletim Técnico do SENAC, Rio de Janeiro, v. 28, n. 2, maio/ago. $2002 \mathrm{~b}$.

LE BRETON, D. Adeus a corpo: antropologia e sociedade. São Paulo: Papirus, 2003. 
Corpo, inteligência e as transformações no mundo do trabalho...

LE BRETON, D. La saveur du monde: une anthropologie des sens. Paris: Métaillé, 2006.

LESSA, S. Para além de Marx?: crítica da teoria do trabalho imaterial. São Paulo: Xamã, 2005.

LIMA, F.P.A.; SILVA, C.A.D. A objetivação do saber prático na concepção de sistemas especialistas: de regras formais a situações de ação. In: Duarte, F. (Org.). Ergonomia e projeto na indústria de processo contínuo. Rio de Janeiro: Lucena, 2002a. p. 84-121.

LIMA, F.P.A.; SILVA, C.A.D. A objetivação do saber prático na concepção de sistemas especialistas: um estudo de caso na indústria cimenteira. In: Duarte, F. (Org.). Ergonomia e projeto na indústria de processo continuo. Rio de Janeiro: Lucena, 2002b. p. 122-172.

MARIE, G. La disparition du travail manuel: vers une métamorphose de la société. Paris: L'Harmattan, 2004.

MARX, K. O capital: crítica da economia política. 14. ed. Rio de Janeiro: Bertrand Brasil, 1994. Livro 1, v.1.

NEGRI, A.; HARDT, M. Empire. Paris: Exils, 2000.

NONAKA, I.; TAKEUCHI, H. Criação de conhecimento na empresa: como as empresas japonesas geram a dinâmica da inovação. Rio de Janeiro: Campus, 1997.

PEZÉ, M. Le deuxième corps. Paris: La Dispute, 2002.

PINTO, A.M.R. O mundo capitalista e as transformaçôes do fordismo: a reabilitação da escola clássica na era das máquinas inteligentes. 1991. 233f. Tese (Doutorado) - Faculdade de Educação, Pontifícia Universidade Católica de São Paulo, São Paulo.

POLANYI, M. Personal knowledge: towards a post-critical philosophy. Chicago: University of Chicago, 1974.

PRADO, E.F.S. Economia política do imaterial. [s.d.a]. Disponível em: <www.econ.fea.usp.br/eleuterio>. Acesso em: 30 maio 2005.

PRADO, E.F.S. Pós-grande indústria: trabalho imaterial e fetichismo. [s.d.b]. Disponível em: <www.econ.fea.usp.br/eleuterio>. Acesso em: 30 maio 2005. 
RABINBACH, A. The human motor: energy, fatigue and the origins of modernity. Los Angeles: University of California, 1992.

VAZQUEZ, A.S. Filosofia da práxis. 4. ed. Rio de Janeiro: Paz \& Terra, 1990.

WOOD, S. The deskilling debate, new technology and work organization. Acta Sociologica, Oslo, v. 30, n. 1, p. 3-24, 1987.

YANARELLA, E.J.; REID, H.G. From "trained gorilla” to "humanware": repoliticizing the body-machine complex between the fordism and post-fordism. In: SChatzKI, T.; NATTER, W. (Org.). The social and political body. New York: The Guilford, 1996. p. 181-219.

ZARIFIAN, P. Objetivo competência: por uma nova lógica. São Paulo: Ática, 2001.

ZUBOFF, S. In the age of the smart machine: the future of work and power. New York: Basic Books, 1988. 